\author{
Christophe Nguyen \\ Radu Christian Boldea \\ Sylvain Roy \\ Tarek Shaarawy \\ Sylvie Uffer \\ André Mermoud
}

\title{
Outflow mechanisms after deep sclerectomy with two different designs of collagen implant in an animal model
}

Received: 3 June 2005

Revised: 3 December 2005

Accepted: 11 January 2006

Published online: 5 April 2006

C) Springer-Verlag 2006
Financial support: Fonds National Suisse pour la Recherche Scientifique $\mathrm{N}^{\circ}$ 32-64103.00.

Financial interest: the study was partly sponsored (implants) by STAAR surgical AG, Nidau, Switzerland.

C. Nguyen - R. C. Boldea - S. Roy T. Shaarawy $\cdot$ S. Uffer $\cdot$ A. Mermoud Jules Gonin Eye Hospital,

University of Lausanne,

Lausanne, Switzerland

T. Shaarawy

Memorial Research Institute

of Ophthalmology,

Giza, Egypt

A. Mermoud $(\bowtie)$

Jules Gonin Eye Hospital,

University of Lausanne,

15, Avenue de France,

1004 Lausanne, Switzerland

e-mail: andre.mermoud@ophtal.vd.ch

Tel.: +41-21-6268111

Fax: +41-21-6268246
Abstract Background: To study experimentally two different shapes of collagen implants (CI) used in deep sclerectomy (DS). The ability to promote drainage vessels, outflow mechanisms, success rates, and biodegradability, were studied prospectively in an animal model. Materials and methods: DS was performed in 20 eyes of ten rabbits. Each rabbit randomly received a cylindrical $\mathrm{CI}$ in one eye, while the other eye received a flat CI. Intraocular pressure (IOP) measurement, ultrasound biomicroscopy (UBM) examination of DS site and simultaneous fluorescein and indocyanin green anterior-segment angiography were performed preoperatively, at 1 and 2 weeks, 1, 2, 3, 6 and 9 months for each eye. At the end of the follow-up period, outflow facility (OF) was measured and histological examinations of the filtration site were performed. Results: In the cylindrical implant group, IOP significantly dropped from a mean preoperative value of $14.8 \pm 2.2 \mathrm{mmHg}$ to a mean postoperative values of $10.9 \pm 3.3,12.5 \pm 2.2,11.8 \pm 2.6$, $11.2 \pm 2.3,10.7 \pm 1.9,14.0 \pm 3.2$, $12.6 \pm 2.4 \mathrm{mmHg}$ at 1,2 weeks, and 1 , 2, 3, 6, and 9 months, respectively. In the flat CI group, IOP significantly dropped from a mean preoperative value of $14.1 \pm 1.8 \mathrm{mmHg}$ to a mean postoperative values of $10.4 \pm 2.7$, $12.7 \pm 1.9,12.5 \pm 3.2,11.2 \pm 1.6,11.6 \pm$ $1.8,11.5 \pm 2.3,11.0 \pm 2.2 \mathrm{mmHg}$ at 1,2 weeks, and at $1,2,3,6$, and 9 months, respectively. UBM images showed a gradual resorption of both type of CI during the first 3 months, and angiographies showed progressive growth of drainage vessels around the filtration site in both groups. The mean OF 9 months postoperatively for the cylindrical CI was $0.53(\mathrm{SD} \pm 0.23) \mathrm{ml} /$ min per $\mathrm{mmHg}$ and was $0.56(\mathrm{SD} \pm$ $0.17) \mathrm{ml} / \mathrm{min}$ per $\mathrm{mmHg}$ for the flat CI $(P=0.6)$. Histological examination revealed excellent biocompatibilty and a high density of drainage vessels in the sclera around the operative site in both groups. Conclusion: Using IOP and OF measurements, UBM, angiography, and histology, we were able to compare two types of CI used as space maintainer in DS. Both CIs showed efficient IOP lowering effect and outflow facility increase, possibly explained by stimulation of drainage vessels growth. Both implants showed excellent biocompatibility. The flat CI showed a slight tendency towards better overall performances.

Keywords Deep sclerectomy ·

Rabbit - Collagen glaucoma drainage device - Glaucoma surgery 


\section{Introduction}

Early glaucoma surgical techniques used full thickness perforation of the sclera [7]. The main disadvantage of these procedures was overfiltration in the early postoperative period, leading to sight threatening complications including ocular hypotony, shallow or flat anterior chamber, choroidal detachment and cataract.

Later on, Cairns [2] and others [11, 20] reported good results performing trabeculectomy under a superficial scleral flap. This flap created a resistance to aqueous outflow and lowered the number of postoperative complications. Nevertheless, the complication rate remained relatively high and the follow-up was still difficult, needing several examinations and additional procedures.

To improve the reproducibility and the safety of filtering procedures, several non-penetrating filtering surgeries have been described in the last 10 years. The principal concept of non-penetration is to create filtration through a natural membrane, which acts as an aqueous humor outflow resistance site, allowing a progressive drop in intraocular pressure (IOP) and avoiding postoperative ocular hypotony and other related complications. The most popular non-penetrating surgical techniques included ab-externo trabeculectomy [1], viscocanalostomy [17, 18], deep sclerectomy [5] and deep sclerectomy with collagen implant [8].

It has been demonstrated in clinical studies that deep sclerectomy is an effective treatment in lowering IOP, thus slowing down glaucoma progression $[10,15]$. The use of implants with deep sclerectomy prevents early fibrosis of the created sclerocorneal space. It has been shown in clinical trials that the use of a collagen implant with deep sclerectomy increases the success rate, compared with deep sclerectomy alone $[6,14]$. The effect of the shape of the implant on the success rate of the surgery has never been studied.

The purpose of our research was to study the effect of the shape of the collagen implant used routinely in deep sclerectomy surgery. The ability to promote draining vessels, the outflow mechanisms, the success rates and the biodegradability, were studied in an animal model.

\section{Materials and methods}

Twenty deep sclerectomies were performed in ten pigmented rabbits. The left and right eyes were randomly assigned to receive either a cylindrical collagen implant measuring $1 \times 1 \times 4 \mathrm{~mm}$ (Fig. 1) or a flat collagen implant measuring $4 \times 4 \times 0.15 \mathrm{~mm}$ (Fig. 2). IOP measurement, ultrasound biomicroscopy (UBM) examination of deep sclerectomy site and simultaneous fluorescein and indocyanin green anterior-segment angiographies $[12,13]$ were performed preoperatively, at 1 and 2 weeks, 1, 2, 3, 6 and 9 months after the surgery for each eye. At the end of the follow-up period, the outflow facility, using the infusion of anterior chamber with constant pressure method, was measured and histological examinations with light microscopy of the filtration site were performed.

\section{Model used}

All experiments were performed on pigmented rabbits with a weight of $2-3 \mathrm{~kg}$. The animals were kept at $21{ }^{\circ} \mathrm{C}$ in a normal 12-h light and 12-h dark cycle. For the experiments (surgery, angiographies, ultrasound biomicroscopy, outflow facility measurements), all animals were anaesthetized by intramuscular injection of $4 \mathrm{ml}$ of a solution of $3 \mathrm{ml}$ ketamine $(50 \mathrm{mg} / \mathrm{ml})$ and $1 \mathrm{ml}$ xylazine $(20 \mathrm{mg} / \mathrm{ml})$. At the end of the study period and while still under anaesthesia, the animals were killed by an intracardiac injection of $5 \mathrm{ml}$ of a solution of sodium pentobarbital $(65 \mathrm{mg} / \mathrm{ml})$.

Experiments were performed in compliance with the ARVO statement for the use of animals in ophthalmic research.

\section{Surgical procedure}

The same surgeon (R.S.) performed all the deep sclerectomies with collagen implants. To expose the surgical site, an intracorneal 6-0 silk traction suture was first placed on the limbal cornea. The conjunctiva was then opened at the limbus in the upper part of the eye and the sclera was exposed. A limbal-based scleral flap measuring $5 \times 5 \mathrm{~mm}$ was dissected using a diamond knife. The deep sclerectomy was then performed leaving a thin layer of deep sclera over the choroid and the ciliary body; the Schlemms's canal was unroofed. At this stage of the surgery, significant aqueous humor filtration through the remaining trabeculum could be observed.

If the eye was randomly selected to receive a cylindrical collagen implant (CGDD-10 implant; Staar Surgical AG,

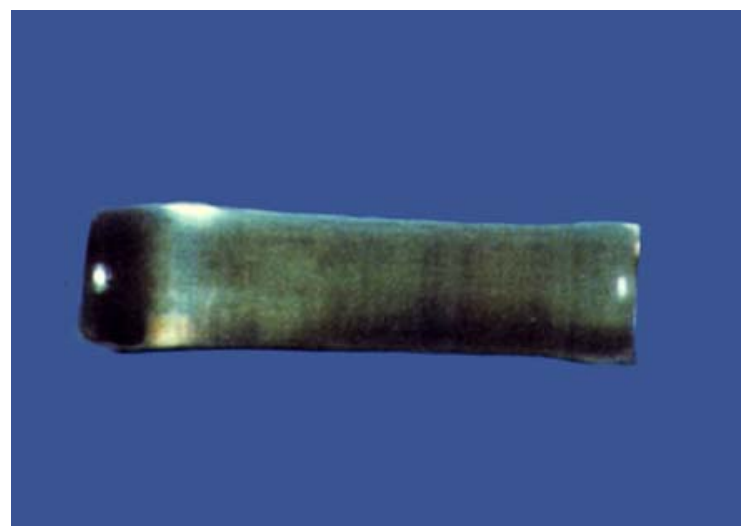

Fig. 1 Cylindrical collagen implant 


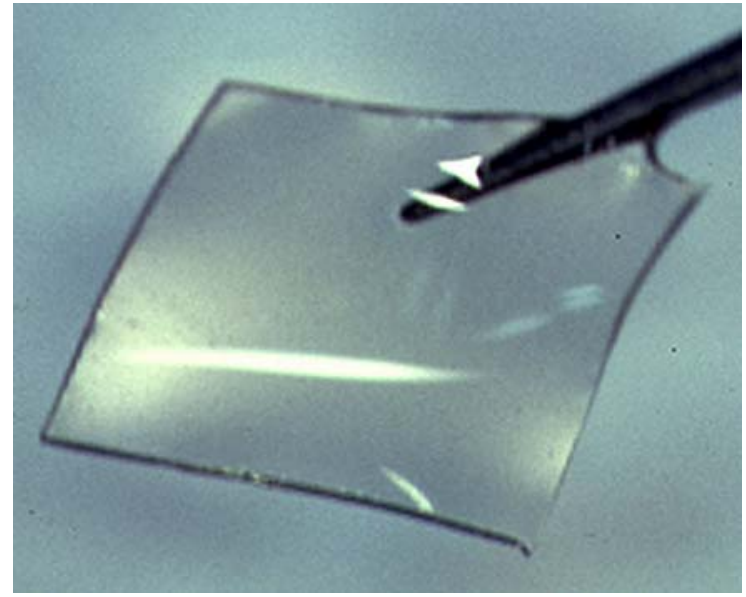

Fig. 2 Flat collagen implant

Nidau, Switzerland), the device measuring $1 \times 1 \times 4 \mathrm{~mm}$ was sutured radially in the scleral bed with a 10/0 nylon suture. The superficial scleral flap was then repositioned over the collagen implant and secured with two loose 10/0 nylon sutures.

If the eye was randomly selected to receive a flat collagen implant (Staar Surgical AG), the device measuring $4 \times 4 \times 0.15 \mathrm{~mm}$ was inserted in the scleral bed without suture. The superficial scleral flap was closed with two $10 / 0$ nylon sutures. In all the eyes, the conjunctiva was then closed with interrupted $8 / 0$ Vycril sutures. After the surgery, tobramycin and dexamethasone (Tobradex; Alcon, Forthworth, Tex., USA) were applied topically twice a day for 3 weeks.

\section{IOP measurements}

The intraocular pressure measurements were performed with a Tono-Pen-XL tonometer (Mentor, Norwell, Mass., USA) under local anaesthesia (Novesin; Ciba Vision, Bülach, Switzerland) [9]. An average of ten consecutive readings was recorded.

\section{Ultrasonic biomicroscopy (UBM)}

High frequency UBM allowed detailed anatomical assessment of the anterior segment of the eye [3]. Using UBM examinations, the evolution of the implant and the operated site over time was observed.

As the intraobserver reliability varies considerably and may be affected by subjective interpretation of visualized landmarks [19], all the examinations were performed by one single observer (N.C).

The Humphrey UBM 840 system (Humphrey Instruments, Inc., San Leandro, Calif., USA) was used to provide high-frequency $(50-\mathrm{MHz})$ ultrasonic scan images. The eye was maintained opened with a eye cup filled with a balanced salt solution (BSS). Images were taken, first radially and then parallelly to the limbus at the site of the surgery.

\section{Anterior segment angiography}

Using fluorescein and indocyanin green anterior-segment angiography after sterile injection of those dyes in the anterior chamber, it was possible to observe the draining pathway of aqueous humor in the rabbit's eye. A preliminary study using this technique has showed the creation of new draining vessels in the rabbit sclera after deep sclerectomy with collagen implant $[12,13]$.

Using the same technique, we compared the formation of new intrascleral drainage vessels induced by deep sclerectomy with the flat and the cylindrical collagen implant.

After performing a limbal paracentesis, $0.2 \mathrm{ml}$ of a solution of $0.1 \mathrm{ml}(1 \mathrm{mg} / \mathrm{ml})$ of indocyanin green (ICG) and $0.1 \mathrm{ml}(0.1 \mathrm{mg} / \mathrm{ml})$ of fluorescein was injected into the anterior chamber. Using a digital camera (Topcon TRC50IA, Tokyo, Japan), several sequenced pictures were taken to visualize the distribution of the dyes within the surgical site. After each angiography, the eyes were treated with 1 drop/day of chloramphenicol and dexamethasone (Spersadex Comp; Novartis Vision, Bülach, Switzerland) for 7 days.

On ICG angiogram, the number of drainage vessels crossed by a virtual line drawn $2 \mathrm{~mm}$ parallel to the limbus, extending from the lateral edge of the superior rectus muscle, down to the upper edge of the lateral rectus muscle was calculated.

\section{Outflow facility measurement}

The mean physiological outflow facility in the rabbit's eyes, was shown to be $0.15 \mu \mathrm{l} / \mathrm{min}$ per $\mathrm{mmHg}$ by Delarive et al. [4]. To evaluate the efficiency of deep sclerectomy with the two different collagen implants, outflow facility was measured 9 months after the surgery, using the anterior chamber infusion with a constant pressure method.

Under microscopic control, rabbit eyes were cannulated with a needle-guided silicone catheter, which was introduced through the corneal limbus into the anterior chamber, $180^{\circ}$ opposite to the site of the surgery. The puncture site was watertight. The catheter was positioned between the anterior plane of the iris and the posterior plane of the cornea without touching either of them. The catheter was connected via polyethylene tubing to a microsyringe pump (type SP 200i, WPI, Sarasota, Fla., USA), which allowed various flow rates ranging from $0.2 \mu \mathrm{l} / \mathrm{h}$ to $426 \mathrm{ml} / \mathrm{h}$.

Via a stopcock, the system was connected to an electronic pressure transducer (type BLPR; WPI), which 
was in turn connected to an amplifier (type BP-1; WPI). The pressure measurements were printed continuously on a chart recorder (type L200E; Linseis GmbH, Selb, Germany).

The system was filled with BSS (Alcon) and cationized ferritin (ferritin from horse spleen $50 \mathrm{mg} / \mathrm{ml}, \mathrm{PM}=800,000$; Biochemica, Fluka Chemie, Buchs, Switzerland), so that ferritin entered the anterior chamber of the eye right from the start of the outflow facility measurements. Ferritin was injected in order to study the site of aqueous filtration with light microscopy. After cannulation, the pressure in the system was increased in successive $10 \mathrm{mmHg}$ steps from $10 \mathrm{mmHg}$ up to $40 \mathrm{mmHg}$. At each pressure level, a constant IOP was maintained using the appropriate infusion rate.

Four pressure levels were obtained. The infusion flow measurements were then plotted against pressure in the system. A regression line was obtained. The slope of this line represented the outflow facility $(\mathrm{C})$.

The outflow facility was then be calculated using the Goldmann equation (Fig. 3).

\section{Histological examinations}

The rabbits' eyes were enucleated just after the animals were killed and fixed in formalin for paraffin embedding. Sections were stained with haematoxylin and eosin (H\&E) and with Prussian blue, which reacts with ferritin. All eyes were coded so that the investigator was blind to the previous type of surgery until the evaluation was completed. Light microscopy was done to assess the route of the aqueous humor from the anterior chamber to the intrascleral space, subconjunctival bleb, uveoscleral tissues and physiological outflow pathways. Structure and surrounding tissue reactions of the surgery site were assessed.

To determine the amount of aqueous humor resorption inside the scleral tissues surrounding the site of surgery, the number of drainage vessels adjacent to the dissection were recorded using light microscopy: ten consecutive sections of each eye were observed with the same magnification $(\times 100)$. The aqueous drainage vessels were identified by their blue colour due to the reaction between ferritin and Prussian blue. For each eye, the number of vessels in ten consecutive sections was recorded first at the surgical site and then $180^{\circ}$ opposite to the surgical site where the tissues were untouched. The results between these two sites were then compared.

$$
\mathrm{C}=\Delta \mathrm{I} / \Delta \mathrm{IOP}
$$

Fig. 3 The Goldmann equation. $C$ outflow facility, $\Delta I$ (I2-I1), where I1 and $\mathrm{I} 2$ are successive inflow rates $(\mu \mathrm{l} / \mathrm{min}), \triangle I O P(\mathrm{P} 2-$ $\mathrm{P} 1)$, where $\mathrm{P} 1$ and $\mathrm{P} 2$ represent IOP at $\mathrm{I} 1$ and $\mathrm{I} 2$, respectively $(\mathrm{mmHg})$

\section{Statistical analysis}

All statistical analysis was performed using Microsoft Excel. Results are expressed as means $\pm \mathrm{SD}$. The differences between the two groups concerning the postoperative IOP, the postoperative outflow facility and the mean number drainage vessels seen histologically, were analyzed by the Student $t$-test for paired comparisons. A $P$-value $<0.05$ was considered statistically significant.

\section{Results}

During all the surgical procedures, no perforation of the trabecular membrane occurred. All the experiments were performed under general anaesthesia and were easy and well tolerated by the animals throughout the study. No eyes presented postoperative inflammation in the anterior chamber. All corneas stayed clear and no endophtalmitis was observed.

IOP

Comparison between mean IOP with the cylindrical implant group and the flat collagen implant group is represented on Fig. 4. In the cylindrical implant group, IOP significantly dropped from a mean preoperative value of $14.8 \pm 2.2 \mathrm{mmHg}$ to mean postoperative values of $10.9 \pm 3.3$, $12.5 \pm 2.2,11.8 \pm 2.6,11.2 \pm 2.3,10.7 \pm 1.9,14.0 \pm 3.2,12.6 \pm$ $2.4 \mathrm{mmHg}$ at 1 and 2 weeks, and at 1, 2, 3, 6, and 9 months, respectively. In the flat collagen implant group, IOP significantly dropped from a mean preoperative value of $14.1 \pm 1.8 \mathrm{mmHg}$ to mean postoperative values of $10.4 \pm 2.7$, $12.7 \pm 1.9,12.5 \pm 3.2,11.2 \pm 1.6,11.6 \pm 1.8,11.5 \pm 2.3,11.0 \pm$ $2.2 \mathrm{mmHg}$ at 1 and 2 weeks, and at 1, 2, 3, 6 and 9 months, respectively. Comparison between the mean IOP in both groups showed that differences were not statistically significant (except for months 6 and 9, when the IOP was higher with the cylindrical implant group).

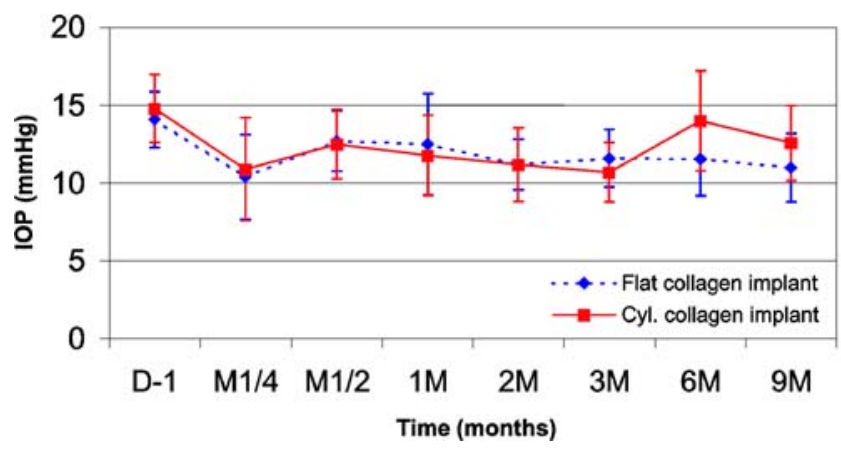

Fig. 4 Comparison between mean IOP (mmHg) after deep sclerectomy with a cylindrical and a flat collagen implant during the 9 months of follow-up 
Angiographies

With both fluorescein and ICG green angiography, the drainage canal (equivalent of Schlemm's canal), the newly created filtration space and the drainage vessels were easily visualized (Fig. 5). In the late phase of angiography, the drainage vessels were better recognized with ICG green, as fluorescein had a tendency to leak from vessels and to dye the sclera surrounding the drainage vessels. Both implants were well recognized in the scleral bed after 1 week, as a well delimited hypofluorescent zone in the intrascleral space. Progressively, both types of implants became less observable and after 3 months, were not visible at all, probably after porcine collagen digestion by rabbit enzymes. The first new drainage vessels were seen 2-4 weeks postoperatively. A progressive growth of drainage vessels around the filtration site was seen in both groups during the first 6 months. Between 6 and 9 months, the mean number of drainage vessels remained unchanged in both groups. Comparison between the average number of drainage vessels seen on angiograms in both groups is represented in Fig. 6.

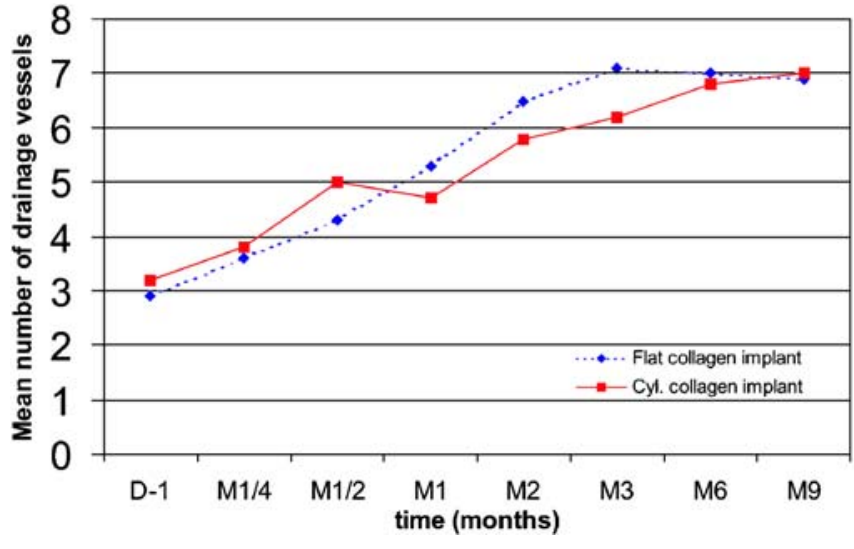

Fig. 6 Comparison between mean number of drainage vessels seen with angiography after deep sclerectomy with a cylindrical and a flat collagen implant during the 9 months of follow-up

\section{UBM}

UBM images of the operative site showed that collagen implants were easily recognized in the intrascleral space during the first postoperative weeks (Fig. 7). By measuring the average mean height of the implants at each examina-
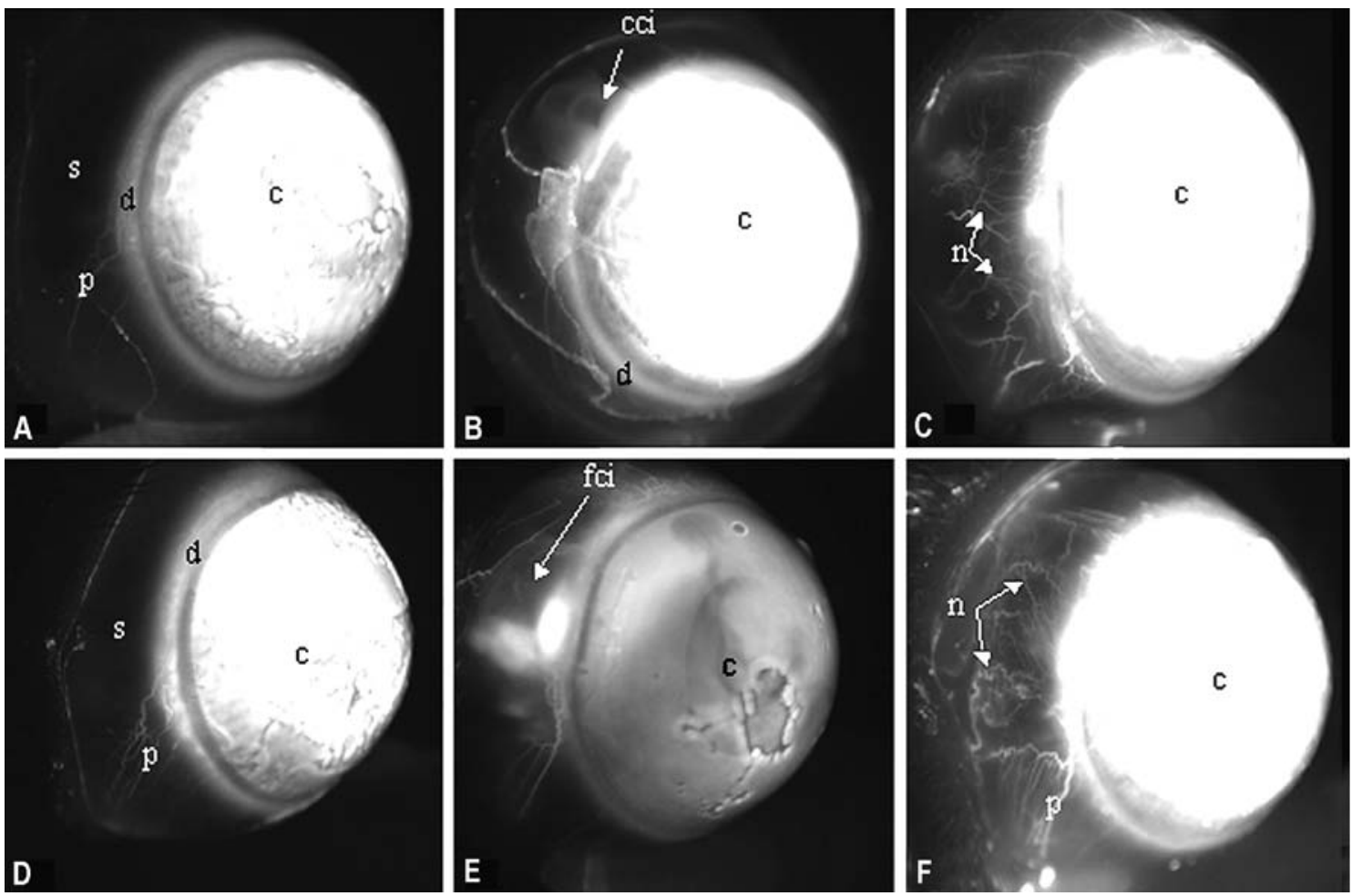

Fig. 5 ICG anterior segment angiographies preoperatively, at 1 week and at 9 months postoperative with a cylindrical implant (a-c) and with a flat collagen implant (d-e). a and $\mathbf{d}$ Preoperatively, the cornea $(c)$, the drainage canal $(d)$ (equivalent of Schlemm's canal), and physiological scleral drainage vessels $(p)$ were hyperfluorescent and easily visualized. As the dye did not leak from vessels, the sclera $(s)$ stayed hypofluorescent. b and e: at 1 week postoperatively, the newly created filtration space and cylindrical implants $(c c i)$ and flat implant $(f c i)$ were clearly visible. $\mathbf{c}$ and $\mathbf{f}$ : at 9 months postoperatively, implants and filtration space were no longer observable, whereas new scleral drainage vessels $(n)$ were now well developed 
tion, a gradual resorption of both collagen implants during the first 3 months was observed. In the flat collagen implant group, the complete resorption time was 2 months, whereas, in the cylindrical collagen implant group, the complete resorption was slightly longer, between 2 and 3 months. Comparison between the average height of both implants in the scleral bed measured with UBM during the 9 month follow-up is represented on Fig. 8.

\section{Outflow facility}

Comparison between the average post-operative outflow facilities in the cylindrical implant group and the flat collagen implant group is represented in Fig. 9. Based on the work of Delarive et al. [4], physiological preoperative outflow facility was considered to be $0.15 \mu \mathrm{l} / \mathrm{min}$ per $\mathrm{mmHg}$. A significant increase in outflow facility was observed 9 months after the surgery in both groups. At 9 months, the average outflow facility for the cylindrical implant was $0.53(\mathrm{SD} \pm 0.23) \mu \mathrm{l} / \mathrm{min}$ per $\mathrm{mm} \mathrm{Hg}$ and was $0.56(\mathrm{SD} \pm 0.17) \mu \mathrm{l} / \mathrm{min}$ per $\mathrm{mm} \mathrm{Hg}$ for the flat implant. The difference between the two groups was not statistically significant $(P=0.6)$.
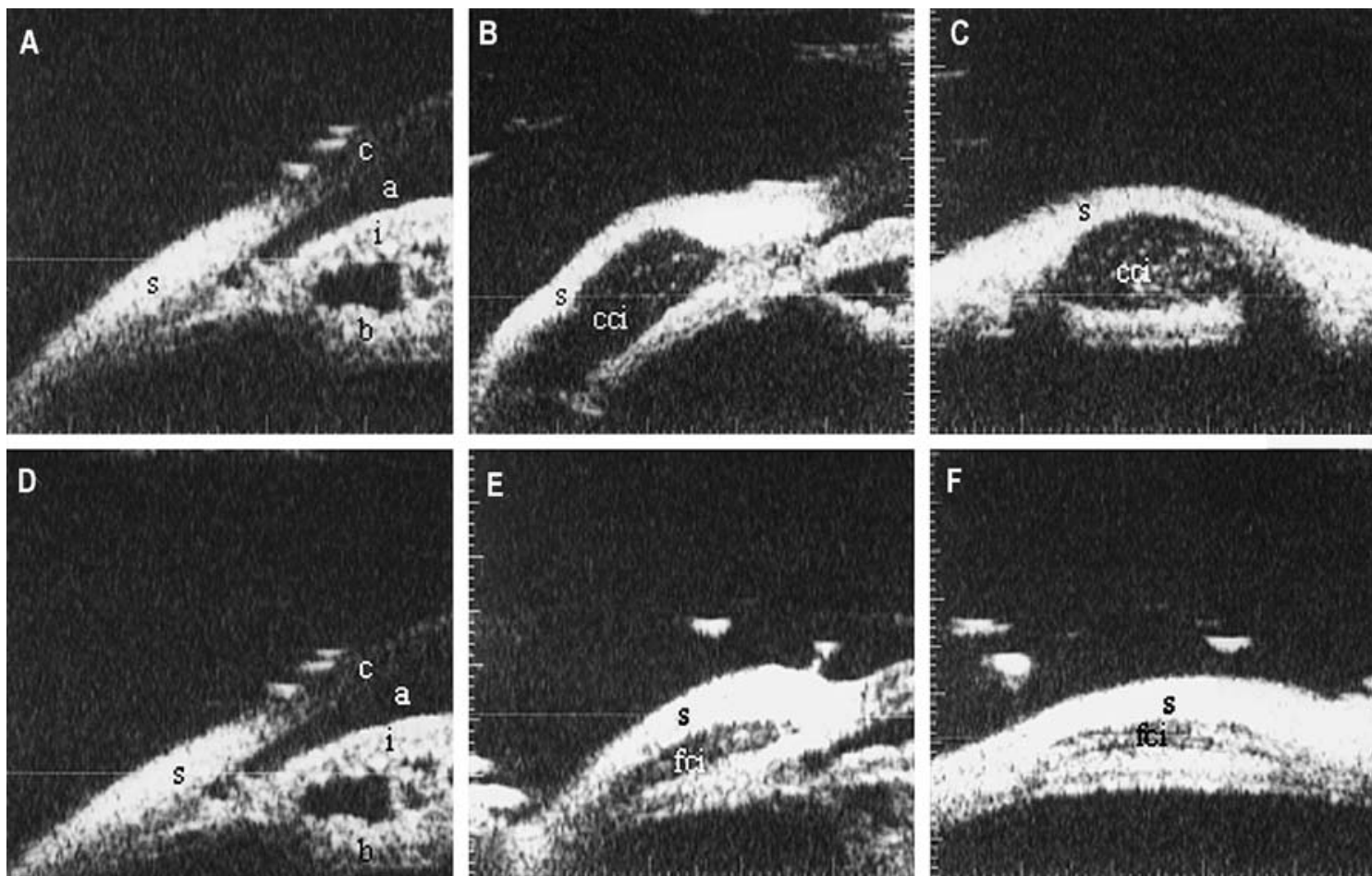

Fig. 7 Ultrasonic biomicroscopy ultrasound preoperatively, and at 1 week (sagittal and frontal view) with a cylindrical collagen implant (a to c) and with a flat collagen implant (d to e). a and $\mathbf{d}$ : preoperative normal anterior segment structures. $a$ anterior chamber,

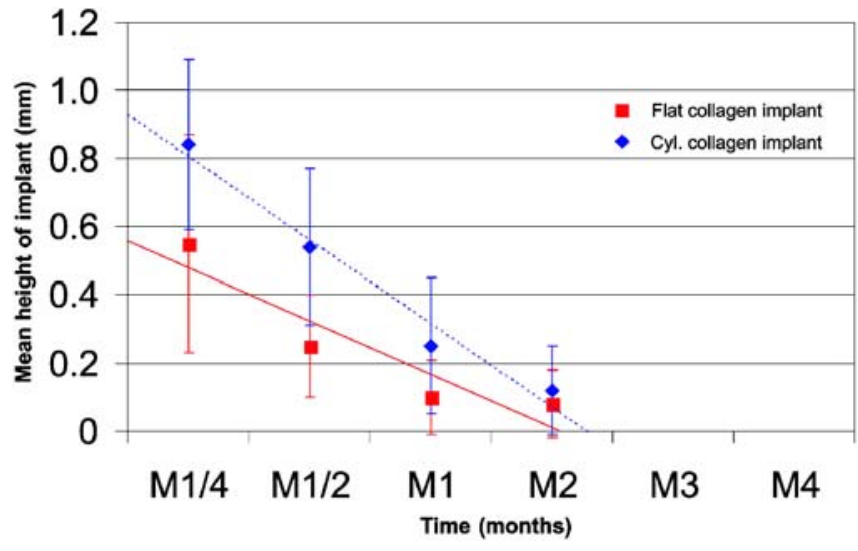

Fig. 8 Comparison between mean height of cylindrical and flat collagen implants during the 9 month follow-up

\section{Histological examinations}

A light microscopic study of the operated site 9 months after the operation revealed the persistence of an intrascleral drainage space in both groups. At that time, the drainage spaces were in both groups all regular and entirely covered by spindle cells [4].Microscopic studies revealed the appearance of new drainage vessels in the sclera adjacent to the dissection site in both surgical groups (Fig. 10). In both groups, the number of new aqueous 
Fig. 9 Comparison between mean postoperative outflow facility after 9 months follow-up with cylindrical and flat collagen implant. $\dagger$ Number published by Delarive et al. [4]

\begin{tabular}{|l|c|c|c|}
\hline & $\begin{array}{c}\text { Cylindrical implant } \\
( \pm \mathrm{SD} ; \mathrm{N}=10)\end{array}$ & $\begin{array}{c}\text { Flat implant } \\
( \pm \mathrm{SD} ; \mathrm{N}=10)\end{array}$ & $\begin{array}{c}\text { P value } \\
\text { (Between cylindrical and } \\
\text { flat implant })\end{array}$ \\
\hline Physiological OF & $0.15 \pm 0.02^{\dagger}$ & $0.15 \pm 0.02^{\dagger}$ & \\
{$[\mu \mathrm{l} / \mathrm{min} / \mathrm{mm} \mathrm{Hg}]$} & $0.53 \pm 0.23$ & $0.56 \pm 0.17$ & $\mathrm{P}=.62$ \\
\hline Mean postoperative $(9 \mathrm{months})$ & & & \\
{$[\mu \mathrm{l} / \mathrm{min} / \mathrm{mm} \mathrm{Hg}]$} & & & \\
\hline
\end{tabular}

drainage vessels in the operated sclera compared to the unoperated sclera was significantly higher at 9 months postoperatively (Fig. 11). In the cylindrical implant group, the mean number of drainage vessels was $8.8 \pm 1.4$ in the unoperated site, and $12.2 \pm 3.0$ in the operated site $(P<0.005)$. In the flat collagen implant group, the mean number of drainage vessels was $8.6 \pm 1.2$ in the operated site, and $11.9 \pm 2.8$ in the unoperated site $(P<0.0005)$. The difference of mean drainage vessels between the two groups was statistically not significant $(P=0.89)$.

\section{Discussion}

Deep sclerectomy with collagen implant was shown to lower usual postoperative complications seen in classical

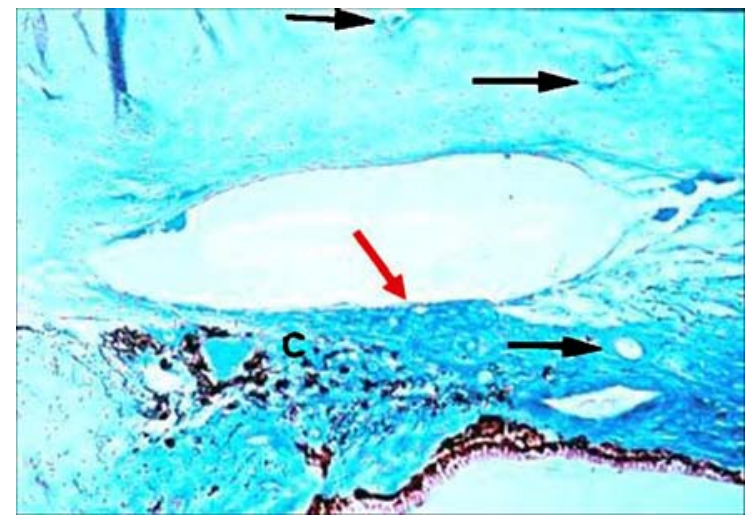

Fig. 10 Histology 9 months post-surgery $(\times 50)$. Spindle cells cover the entire wall of the canal (red arrow). New aqueous drainage vessels surrounding the operated site are clearly visible (arrow). $C$ ciliary body trabeculectomy. In the aim to maintain the created filtration space under the scleral flap patent, a biologically neutral implant is put in the intrascleral space. Koslov [8] proposed a collagen implant that is resorbed within 6-9 months. Sourdille [16] uses a reticulated hyaluronic acid implant and Dahan uses a non-resorbable Hema implant (Ioltech, La Rochelle, France).

In clinical practice, the usual collagen implant has a cylindrical shape. The use of a flat collagen implant in deep sclerectomy offers several advantages compared to the classical cylindrical collagen implant: no suture is needed to maintain the flat implant in the scleral bed, the flat collagen implant can be used to close a perforation of the trabeculo-Descemet's membrane, and the intrascleral surface occupied by the flat implant is bigger. It is of great interest to know if by changing the shape of the collagen implant, there is also an effect on outflow mechanisms, and then on success rates.

A significant IOP decrease was observed during all the follow-up after deep sclerectomy using both cylindrical and collagen implant. The IOP decrease was quite similar with both implants, except for 6 and 9 months, when the mean IOP was lower with the cylindrical implant. Even if the experiments were performed on rabbits with normal intraocular pressure, the significant decrease in IOP at all examinations after the surgery, shows the efficiency in lowering IOP of deep sclerectomy with collagen implant.

Anterior-segment angiography with simultaneous use of fluorescein and ICG green allowed visualisation of the the shape of implants and the aqueous draining pathway. After 3 months, both implants have completely disappeared on angiograms. In contrast, a progressive growth of drainage vessels was seen during the first 6 months, with no significant difference with respect to the shape of implant. 
Fig. 11 Comparison between mean number of drainage vessels seen at histology examination at the surgery site and $180^{\circ}$ from surgery site at 9 months, with both implants

\begin{tabular}{|c|c|c|}
\hline & Cylindrical implant & Flat implant \\
\hline At surgery site & 12.2 & 11.9 \\
\hline $180^{\circ}$ from surgery site & 8.8 & 8.6 \\
\hline $\begin{array}{c}\text { Student's T test } \\
\text { (difference between surgery site and } \\
180^{\circ} \text { opposite) }\end{array}$ & $\mathrm{p}<.005$ & $\mathrm{p}<.0005$ \\
\hline
\end{tabular}

With UBM images, both cylindrical and flat collagen implants were easily observed during the first postoperative weeks, occupying a large space under the scleral flap. The flat collagen implant's height went from $0.15 \mathrm{~mm}$ (dry state) to approximately $0.6 \mathrm{~mm}$ after the implant was placed in the intrascleral space (wet state), while the height of the cylindrical collagen implant remained about the same. Complete resorption of implants by rabbit collagenases took between 2 and 3 months, as at that time, both types of implant could not been seen with UBM. The flat collagen was resorbed faster than the cylindrical collagen implant. The complete resorption of porcine collagen was shown to be faster in rabbit eyes than in human eyes, where complete resorption occurred between 6 and 9 months [3].

Light microscopy studies revealed the persistence of a drainage canal after 9 months in both cylindrical and collagen implant sections: the canals were regular and completely covered with spindle cells in both groups. In Delarive et al.'s study [4], comparing histological findings after deep sclerectomy with a cylindrical implant and without, the main difference was the presence of spindle cells lining the walls of this canal in deep sclerectomy with collagen implant sections: these spindle cells were sparsely present 2 months after the surgery, and 6 months postoperatively, covering the entire wall of the canal. In comparison, in deep sclerectomy sections, an irregular canal without spindle cells was observed.

Drainage vessels observed on our sections were significantly higher at the surgery site, compared with $180^{\circ}$ from surgery site, confirming the development of new intrascleral drainage vessels around the surgery site. The difference between the mean number of drainage vessels at the surgery site with both implants was not statistically significant.

After 9 months, the outflow facility was significantly increased in both groups, compared with the physiological outflow facility of the rabbit's eye. Comparing these results with those of Delarive et al. at the same postoperative time [4], the value of outflow increase was similar with the use of the same type of implant $(0.53(\mathrm{SD} \pm 0.23) \mu \mathrm{l} / \mathrm{min}$ per $\mathrm{mmHg}$ in our series and $0.52 \pm 0.28 \mu \mathrm{l} / \mathrm{min}$ per $\mathrm{mmHg}$ in Delarive's series). Knowing that they found a value of $0.46 \pm 0.07 \mu \mathrm{l} / \mathrm{min}$ per $\mathrm{mmHg}$ after deep sclerectomy without implant, the increase of outflow facility seems to be more important when a collagen implant is used.

The collagen implant was well tolerated by rabbit tissues, since no inflammatory response was observed during the entire study.

In conclusion, using IOP and outflow measurements, UBM, angiography, and histology, we were able to study and compare two types of collagen implants used as space maintainers in deep sclerectomy. Both collagen implants showed an outflow facility increase partially explained by the stimulated growth of drainage vessels, and efficient IOP lowering effect. Both implants were well tolerated with respect to biocompatibility. Except for the average number of drainage vessels seen on histology sections, the flat collagen implant showed a slight tendency towards better overall performance. However, the differences observed were not statistically significant. A study with bigger numbers of rabbits might confirm this tendency. For the surgeon, it means that the more convenient flat collagen implant could be used in deep sclerectomy with a success rate at least as good as with the classical cylindrical collagen implant. 


\section{References}

1. Arenas E (1991) Trabeculectomy abexterno. Highl Ophthalmol 19:59-66

2. Cairns JE (1968) Trabeculectomy. Preliminary report. Am J Ophtalmol 66:673

3. Chiou AGY, Mermoud A, Hédiguer SEA, Faggioni SEA, Faggioni R (1996) Ultrasound biomicroscopy of eyes undergoing deep sclerectomy with collagen implant. Br J Ophthalmol 80: 541-544

4. Delarive T, Rossier A, Rossier S, Ravinet E, Shaarawy T, Mermoud A (2003) Aqueous dynamic and histological findings after deep sclerectomy with collagen implant in an animal model. Br J Ophthalmol 87:1340-1344

5. Fyodorov SN (1989) Non-penetrating deep sclerectomy in open angle glaucoma. Eye Microsurgery 3:52-55

6. Karlen M, Sanchez E, Schnyder C, Sickenberg M, Mermoud A (1999) Deep sclerectomy with collagen implant: medium term results. $\mathrm{Br} \mathrm{J}$ Ophthalmol 83:6-11

7. Katz LJ, Spaeth GL (1989) Filtration surgery. In: Ritch R, Shields B, Krupin $\mathrm{T}$ (eds) The glaucomas. Mosby, St Louis, Mo., pp 653-696
8. Kozlov VI, Bagrov SN, Anisimova SY, Opisov AV, Mogilevtsev VV (1990) Non-penetrating deep sclerectomy with collagen. Eye Microsurgery 3:44-46

9. Mermoud A, Baerveld G, Minckler DS, Lee MB, Rao NA (1995) Measurement of rabbit intraocular pressure with the Tonopen. Ophtalmologica 209: 275-277

10. Mermoud A, Schnyder CC, Sickenberg M, Chiou AG, Hediguer SE, Faggioni R (1999) Comparison of deep sclerectomy with collagen implant and trabeculectomy in open-angle glaucoma. J Cataract Refract Surg 25:323-31

11. Molteno ACB, Bosma NJ, Honours BSC, Kittelson JM (1999) Otago glaucoma surgery, outcome study: longterm results of trabeculectomy 19761995. Ophthalmology 106:1742-1750

12. Roy S, Perez D, Curchod M, Boldea R, Mermoud A (1999) Filtration Imaging after deep sclerectomy in the rabbit. Ophthalmic Res, September 31:S1-257

13. Roy S, Boldea R, Perez D, Curchod M, Mermoud A (2000) Visualisation du système d'écoulement de l'humeur aqueuse chez le lapin avec la fluorescéine et le vert d'indocyanine. Klin Monatsbl Augenheilkd 216:305-308

14. Sanchez E, Schnyder CC, Sickenberg $M$ et al (1997) Deep sclerectomy: results with and without collagen implant. Int Ophthalmol 20:157-162
15. Shaarawy T, Karlen M, Schnyder C, Achache F, Sanchez E, Mermoud A (2001) Five-year results of deep sclerectomy with collagen implant.

J Cataract Refract Surg 27:1770-1778

16. Sourdille Ph, Santiago PY, Ducourneau Y (1999) Non-perforating surgery of the trabeculum with reticulated hyaluronic acid implant. J Fr Ophtalmol 22:794-797

17. Stegmann RC (1995) Viscocanalostomy: a new surgical technique for open angle glaucoma. An Inst Barraquer Spain 25:229-232

18. Stegmann RC, Pienaar A, Miller D (1999) Viscocanalostomy for openangle glaucoma in black African patients. J Cataract Refract Surg 25: 316-321

19. Tello C, Liebmann J, Potash SD, Cohen H, Ritch R (1994) Measurement of ultrasound biomicroscopy images: intraobserver reliability. Invest Ophthalmol Vis Sci 35:3549-52

20. Watson PG, Jakeman C, Ozturk M, Barnett MF, Barnett F, Khaw KTs (1990) The complications of trabeculectomy (a 20 year follow-up). Eye $4: 425-438$ 